国

education \& training start a portfolio that you begin to appreciate its potential benefits (Rees \& Sheard, 2004), with the opportunity for reflective learning being developed (Roberts et al, 2002).

Preliminary evidence shows that educational portfolios may benefit the educational process but additional studies are needed to confirm this. Whatever their efficacy, they are here to stay. This survey reinforces the need to make portfolios a compulsory feature of continued learning beyond the foundation years, with clear explanations regarding their content and rationale, otherwise their use may remain low.

\section{Declaration of interest}

None.

\section{References}

CHALLIS, M., MATHERS, A., HOWE, N. et al (1997) Portfolio-based learning: continuing education for general practitioners - a mid-point evaluation. Medical Education, 31 22-26.

COLE, G. (2005) The definition of 'portfolio'. Medical Education, 39, $1140-1142$

DORNAN, T., CARROLL, C. \& PARBOOSINGH, J. (2002) An electronic learning portfolio for reflective continuing professional development. Medical Education, 36, 767-769.

DRIESSEN, E., VAN TARTWIJK, J., OVEREEM, K., et al (2005) Conditions for successful reflective use of portfolios in undergraduate medical education. Medical Education, 39, 1230-1235.

FINLAY, I., MAUGHAN,T. \& WEBSTER, D. (1998) A randomized controlled study of portfolio learning in undergraduate cancer education. Medical Education, 32, 172-176.

LONKA, K., SLOTTE, V., HALTTUNEN, M., et al (2001) Portfolios as a learning tool in obstetrics and gynaecology undergraduate teaching. Medical Education, 35, 1125-1130.

MCMULLAN, M. (2006) Students' perceptions on the use of portfolios in pre-registration nursing education: a questionnaire survey. International Journal of Nursing Studies, 43, 333 343.

MODERNISING MEDICAL CAREERS (2005) Foundation Learning Portfolio. http://www.mmc.nhs.uk/download/ Foundation\%20LP_Updated_2.pdf

REES, C. \& SHEARD, C. (2004) Undergraduate medical students' views about a reflective portfolio assessment of their communication skills learning. Medical Education, 38, 125-128.

ROBERTS, C., NEWBLE, D. \& O'ROURKE, A. (2002) Portfolio-based assessments in medical education: are they valid and reliable for summative purposes? Medical Education, 36, 899-900.

SNADDEN, D. \& THOMAS, M. (1998) Portfolio learning in general practice vocational training - does it work? Medical Education, 32, 401-406.

SNADDEN, D.,THOMAS, M., GRIFFIN, E., et al (1996) Portfolio-based learning and general practice vocationa training. Medical Education, 30, 148-152.

WILKINSON,T., CHALLIS, M., HOBMA, S., et al (2002) The use of portfolios for assessment of the competence and REES C (2005) The use (and abuse) of performance of doctors in practice. the term 'portfolio'. Medical Education, Medical Education, 36, 918-924. $39,436-437$.

Kitty Seed Senior House Officer in Psychiatry, South London and Maudsley NHS FoundationTrust, London, Lisa Davies Consultant, Odgers, Ray and Berndtson, Hanover Square, London, *Ronan J. Mclvor Consultant Psychiatrist and Honorary Senior Lecturer, Maudsley Hospital, 103 Denmark Hill, London SE5 8AZ, email: ronan.mcivor@slam.nhs.uk

\title{
Service user involvement in psychiatric training: a practical perspective
}

The systematic involvement of service users (patients or clients; McGuire-Snieckus et al, 2003) and carers in an active educational role in psychiatric training is a relatively recent development. The National Service Framework for Mental Health states that 'Service users and carers should be involved in planning, providing and evaluating training for all health care professionals' (Department of Health, 1999). The Royal College of Psychiatrists declared that from June 2005 all psychiatric trainees must have training from service users or carers. This is a sizeable shift away from traditional medical teaching, where patients have been involved only in a passive way, as the possessor of symptoms and signs, with teaching delivered by experienced clinicians and academics. The reasons behind these changes have been discussed frequently in recent medical literature (Livingston \& Cooper, 2004). The primary arguments for this initiative are that service users have a unique understanding of their illness and are best placed to judge trainees on their empathy and communication skills. Increasingly, service users' views are being taken into account in training and examination of medical students and doctors (Vijayakrishnan et al, 2006).
Although the need for these changes has been well documented, less has been said about how they should be implemented. For those involved in the organisation and delivery of training to junior psychiatrists, these proposals may seem daunting. The helpful article by Fadden et al (2005) suggests ways in which the process may be taken forwards, giving suggestions and pitfalls regarding recruitment, preparation and process. But how easy is it to translate these ideas into practice?

\section{Our perspective}

Three of the authors (O.H., R.M., N.T.) are honorary clinical lecturers at the University of Birmingham. In conjunction with consultant supervisors they are responsible for the delivery of courses for senior house officers (SHOs) in preparation for parts I and II of the Membership of the Royal College of Psychiatrists (MRCPsych) examination. These courses are attended by SHOs from three local training schemes.

Traditionally these mandatory courses have consisted of three hour-long lectures, run on a weekly 
basis, supplemented by practical sessions. However, involvement of service users and carers has rarely been a feature. In light of the recent impetus, we were given a mandate to begin introducing service users into the established course. This gave us the opportunity to reflect on and update our practice. We considered recruitment of suitable users and candidates, learning outcomes, feedback, support and remuneration. These issues were discussed at the MRCPsych course board meeting, attended by consultants (including the Director of Medical Education), postgraduate medical education administrators, honorary clinical lecturers and trainee representatives.

\section{Initial changes}

The initial changes introduced pilot sessions, using service users carefully selected by experienced lecturers. Choosing suitable candidates involved consideration of those who would have reasonable experience of, and perspective on mental healthcare, be reliable, not be intimidated by addressing up to 50 doctors and have an ability to take an objective overview of their experience.

Service users were chosen from general adult and forensic backgrounds, along with a carer of an older adult patient. Sessions were moderated by an experienced clinician. The clinician acted as mentor, explaining the aims of the course and the learning outcomes. The initial sessions consisted of an introduction and explanation by the moderator, a talk on a specific aspect of their experience of mental health services from the user and then an opportunity for questions and discussion. The moderator aimed, in as non-intrusive fashion as possible, to support the user, address inappropriate or difficult questions and assist in directing discussions. These pilot sessions were used for mainstream topics such as schizophrenia and bipolar disorder.

Each trainee was asked to compete an anonymous Likert scale feedback form, rating relevance, content and delivery, with room for additional comments. The initial feedback from trainees was extremely positive; for combined service user lectures, mean scores for the respective categories above were 4.6, 4.5 and 4.6, each out of a possible 5 . This compares favourably with the course's traditional lectures. On the whole trainees reported enthusiasm for an alternative viewpoint on these disorders, with comments such as 'enlightening and fascinating', 'useful perspective' and 'refreshing'. Many had never had the opportunity to hear a service user talk so candidly about their experiences, without the agenda of diagnosis or treatment hindering the encounter. A minority, less than $4 \%$ of all completed forms, however, conveyed that they did not feel such a talk was directly relevant to their MRCPsych examination preparation. This diversity of feedback is in keeping with the limited existing research in the area (Vijayakrishnan et al, 2006).

Following the feedback from these initial sessions we began to develop plans on how to proceed. It was agreed that the involvement of service users needed to become more structured. The main points of planning were formulation of learning objectives, recruitment of a core group of service users and carers, more support for those involved, remuneration, feedback and representation of users and carers on the course board.

\section{Learning objectives}

It was agreed that learning objectives needed to be formulated by the moderator in conjunction with the service user. For initial sessions, these tended to be generalised, such as

- improve understanding of subjective experience of the disorder

- understand the impact of admission under the Mental Health Act 1983.

However, it is envisaged that with the progression of service user participation, these discussions, and in turn the learning outcomes, will become more refined.

\section{Recruitment and remuneration}

It was considered vital that those carers and service users who contributed to the course were on an equal footing with the moderators and professionals who comprised the other speakers. To this end, each person was paid the same standard disbursement through the Department of Postgraduate Medical Education. This has been accepted by all involved, without difficulties. Those receiving benefits were directed towards appropriate agencies to advise them about the possible effects that earning money might have on their benefits.

To date, recruitment of some speakers has been through people the course organisers have known directly; many have been longstanding patients with valuable perspectives, who are currently well, with the resilience to tackle inquisitive SHOs. Others came from specific services, such as the Early Intervention Service for Bipolar Disorders. They needed to be reasonably articulate and able to some degree to be objective about their own experiences (Fadden et al, 2005). Others have been recruited through their prominence among voluntary agencies and support groups. Occasionally a colleague or similar professional who has personal experience of being a carer has agreed to assist. Voluntary organisations such as Mind, Rethink, Care Services Improvement Partnership and the Alzheimer's Association are valuable resources.

We intend to make future recruitment more structured, with advertisement throughout local trusts and voluntary organisations. Prospective participants will be interviewed as per standard recruitment procedures, offered relevant training and support and evaluated to ensure standards are met. The longer-term aim will be to establish a pool of motivated, experienced speakers with a range of skills. This will help avoid burnout of a small number of overused speakers.

\section{Feedback}

As with all other sessions on the course, each trainee is asked to fill in a feedback form, as described above. This 
F

education \& training allows SHOs to offer constructive comments in an attempt to improve the course. All speakers are provided with a summary of their feedback.

\section{Future plans}

Recently, we formed a 'service user and carer group'; all those who have spoken on the courses to date were invited. A representative of the consultant body and the specialist registrars also attended, together with administrative support. The meeting brought together all parties involved with expanding service user involvement.

The aim was to facilitate the further introduction of similar sessions and to plan for the future. To improve service users' understanding, there were presentations on the training of psychiatrists, the courses and the MRCPsych examinations. The College impetus was explained, as was the future direction of psychiatric training.

After discussing the changes introduced so far, service users gave feedback from their sessions. Overall they reported enjoying the experience and had encountered few problems. One person had found the experience difficult because of the personal nature of some questions, and the importance of the role of facilitator was emphasised. Several suggestions were made for changes, such as to room arrangements, group size or more time for questions. The meeting allowed open dialogue in an informal environment, in order to stimulate new ideas and methods.

This group will continue to meet and is seen as the next stage for us in expanding the role of service users and carers in psychiatric training. It will be important to develop service user involvement with the course board, which oversees development and structure of the course. However, to do this in a meaningful fashion will require careful planning. Too often in such circumstances, service users are included as a token gesture, without real support, and are often inhibited and unable to participate in any manner of consequence. Therefore currently service user/carer feedback remains via the doctors who attend both the 'service user and carer group' and MRCPsych course board meetings.

\section{Conclusions}

Introducing involvement of service users and carers into psychiatric training is valuable, however, it is not without its difficulties. As a relatively recent innovation, those charged with the organisation of courses for trainees face several challenges in implementing these changes.
Introduction of these changes needs to handled sensitively for the benefit of users, carers, existing teachers and those being taught. Reservations have been expressed by some trainees regarding the relevance of service user training to MRCPsych examinations. Junior doctors may, at times, become overly focused on passing examinations as the ultimate goal of their training, rather than seeing examinations as one of several methods of ensuring an adequate standard has been attained. In fact, the true goal of training must be preparation to become a competent and caring doctor, and when seen in this light the need for involvement of those receiving the service becomes clear.

It is hoped that this article will be beneficial for those with responsibility for implementing the changes. There are undoubtedly many other successful methods to mimic and modify, and pitfalls to avoid. Clearly, further research and audit will be important in informing future developments.

\section{Declaration of interest}

None.

\section{Acknowledgements}

We thank all those involved in service user and carer contributions to the courses, including administrative support.

\section{References}

DEPARTMENT OF HEALTH (1999) The National Service Framework for Mental Health. Department of Health.

FADDEN, G., SHOOTER, M. \& HOLSGROVE, G. (2005) Involving carers and service users in the training of psychiatrists. Psychiatric Bulletin, 29 , $270-274$.

LIVINGSTON, G. \& COOPER, C. (2004) User and carer involvement in mental health training. Advances in Psychiatric MCGUIRE-SNIECKUS, R, MCCABE, R \& PRIEBE, S. (2003) Patient, client or service user? A survey of patient preferences of dress and address of six mental health professions. Psychiatric Bulletin, 27, 305-308.

VIJAYAKRISHNAN, A., RUTHERFORD, J., MLLLER, S., et al (2006) Service user involvement in training: the trainees view. Psychiatric Bulletin, 30, 303-305

*Owen Haeney Honorary Clinical Lecturer, University of Birmingham, Specialist Registrar in Forensic Psychiatry, Reaside Clinic, Birmingham Great Park, Rubery, Birmingham B45 9BE, email: owen.haeney@bsmht.nhs.uk, Rajesh Moholkar Honorary Clinical Lecturer, University of Birmingham, Specialist Registrar in Forensic Psychiatry, Hillis Lodge, Birmingham, NicholasTaylor Honorary Clinical Lecturer, University of Birmingham, Specialist Registrar in Forensic Psychiatry, Hatherton Centre, Stafford, Thomas Harrison Consultant Psychiatrist, Assertive OutreachTeam, Scarborough House, Birmingham 